\title{
Near-infrared fluorescent amphiphilic polycation wrapped magnetite nanoparticles as multimodality probes
}

\author{
WANG Dan ${ }^{1 \dagger}$, SU Hong Ying ${ }^{1 \dagger}$, LIU YanHong $^{1}$, WU ChangQiang ${ }^{1}$, XIA ChunChao $^{2}$, \\ SUN JiaYu ${ }^{2}$, GAO FaBao ${ }^{2}$, GONG QiYong ${ }^{2}$, SONG Bin ${ }^{2} \& \mathrm{AI} \mathrm{Hua}^{1,2^{*}}$ \\ ${ }^{1}$ National Engineering Research Center for Biomaterials, Sichuan University, Chengdu 610064, China; \\ ${ }^{2}$ Department of Radiology, West China Hospital, Sichuan University, Chengdu 610041, China
}

Received January 16, 2012; accepted January 31, 2012; published online April 24, 2012

\begin{abstract}
Construction of multifunctional/multimodality nanoparticles for cancer diagnosis and therapy has become an attractive area of investigation. In this report, we designed a multimodality nanoprobe for cell labeling, and can be detectable by both magnetic resonance and near infrared (NIR) fluorescence imaging. Multiple hydrophobic superparamagnetic iron oxide (SPIO) nanocrystals are self-assembled into nanocomposites in water phase with the help of partially alkylated hyperbranched polycation, polyethylenimine (PEI), which already conjugated with the indocyanine dye Cy5.5 and can be used for cell imaging under NIR fluorescence imaging. The amphiphilic PEI/SPIO nanocomposites have a strong $T_{2}$ relaxivity. The iron uptake process in MCF-7/Adr displays a time dependent behavior. Confocal laser scanning microscopy reveals that the nanoprobes are internalized into the cytoplasm of MCF-7/Adr after $24 \mathrm{~h}$ labeling. Both MR and NIR fluorescence imaging showed strong image contrast against unlabeled cells. Under a clinical MRI scanner, labeled cells in gelatin phantom present much darker images than controlled ones. The $T_{2}$ relaxation rate of the labeled cells is $98.2 \mathrm{~s}^{-1}$, significantly higher than that of the control ones of $2.3 \mathrm{~s}^{-1}$. This study provides an important alternative to label MCF-7/Adr at optimized low dosages with high efficiency, and may be useful to label other biologically important cells and track their behaviors in vivo.
\end{abstract}

multifunctional, superparamagnetic iron oxide, multimodality, magnetic resonance imaging, near infrared fluorescence imaging

Citation: Wang D, Su H Y, Liu Y H, et al. Near-infrared fluorescent amphiphilic polycation wrapped magnetite nanoparticles as multimodality probes. Chin Sci Bull, 2012, 57: 4012-4018, doi: 10.1007/s11434-012-5073-7

Nanotechnology used for cancer diagnosis and therapy has received enormous attentions in recent years [1-3]. Especially, efforts have been devoted to designing multifunctional nanosystems that can improve in vivo imaging sensitivity, drug loading capacity, drug delivery efficiency and controlled drug release capabilities [4,5].

Magnetic resonance imaging (MRI) is a widely used clinical imaging modality with several advantages including excellent temporal and spatial resolution, safe imaging without using high-energy radiation, deep tissue penetration and long effective imaging window [6-8]. Besides, application of MRI for drug discovery has proven to be effective,

\footnotetext{
$\dagger$ These authors contributed equally to this work.
}

*Corresponding author (email: huaai@scu.edu.cn) especially when used for characterization of disease models and therapeutic efficacy $[9,10]$. In particular, with the help of superparamagnetic iron oxide (SPIO) nanoparticle based contrast agents, MRI can visualize disease-specific biomarkers at both molecular and cellular levels [11,12]. SPIO nanoparticles are strong enhancers of proton relaxation with superior MR transverse relaxation $\left(T_{2}\right)$ shortening effects, and can be used at a much lower concentration than paramagnetic agents $[13,14]$. One of the interesting discoveries is that when multiple SPIO nanoparticles are gathered together and formed nanoclusters, their $T_{2}$ relaxivity is greatly improved over single SPIO nanoparticles, leading to a much better signal contrast enhancement [15]. Previously, we reported that multiple SPIO nanocrystals loaded alkyl- 
PEI micelles have an $r_{2}$ of up to $345 \mathrm{Fe}^{\mathrm{mM}} \mathrm{m}^{-1} \mathrm{~s}^{-1}(1 \mathrm{M}=$ $\left.1 \mathrm{~mol} \mathrm{~L}^{-1}\right)$, and much higher than single SPIO nanocrystal containing ones $[16,17]$.

Near-infrared (NIR) fluorophore imaging possesses enhanced light penetration depth through living tissues because of reduced absorbance by tissue pigments and hemoglobin in the NIR region (700-900 nm) [18]. NIR imaging has a strong sensitivity and offers a unique advantage for the imaging of small pathophysiological changes [19]. Several groups have demonstrated that NIR fluorescent dye Cy5.5 is a promising probe for the in vivo imaging of tumors [20-22]. A combination of MRI and NIR imaging modalities can provide useful information with high spatial resolution and good sensitivity, which requires the availability of dual modality probes.

In this work, we have developed an amphiphilic polyethylenimine $25 \mathrm{k}$ (PEI25k) conjugated with NIR fluorescent dye Cy5.5, and it was used for encapsulation of multiple hydrophobic SPIO nanoparticles to form a multimodality probe for cell labeling capability. We evaluated the cell labeling efficiency and intracellular distribution of the SPIO nanocomposite for different incubation periods. MR and optical imaging sensitivity of MCF-7/Adr cells labeled with SPIO nanocomposites was studied under a clinical MRI scanner and a small-animal imaging system accordingly.

\section{Materials and methods}

\subsection{Synthesis of superparamagnetic iron oxide (SPIO) nanocrystals}

Iron(III) acetylacetonate, 1,2-hexadecanediol (97\%), benzyl ether (99\%), oleic acid (90\%), and oleylamine (>70\%) were purchased from Aldrich Chemical Co. and used as received. Detailed synthetic method for SPIO nanocrystals was described in a previous publication by Sun et al. [23]. Briefly, $\mathrm{Fe}(\mathrm{acac})_{3}(1 \mathrm{mmol})$ was mixed with 1,2 -hexadecanediol (5 $\mathrm{mmol})$, oleic acid $(3 \mathrm{mmol})$, and oleylamine $(3 \mathrm{mmol})$ in benzyl ether $(10 \mathrm{~mL})$ under argon protection. The mixture was then heated to reflux $\left(300^{\circ} \mathrm{C}\right)$ for $1 \mathrm{~h}$. After cooling to room temperature, the solution was treated with ethanol to yield a dark-brown precipitate. The product was redispersed in hexane in the presence of oleic acid and oleylamine and precipitated with ethanol for a few times. Finally, these nanocrystals were dispersed in hexane for storage. The size distribution of SPIO nanoparticle was characterized by dynamic light scattering (DLS).

\subsection{Synthesis and characterization of alkyl-PEI25k- GLY/Cy5.5}

Branched PEI25k (MW 25 kD) was obtained from Aldrich and reacted with 1-iodododecane (Alfa Aesar) in ethanol following literature procedures [24]. Usually, to a $0.812 \mathrm{~g}$ portion of dry PEI dissolved in $10 \mathrm{~mL}$ of absolute ethanol dehydrated by sodium previously, $0.67 \mathrm{~g}$ of 1-iodododecane was added. The whole reaction system was placed in oil bath at $55^{\circ} \mathrm{C}$ for $6 \mathrm{~h}$ with magnetic stirring, then overnight at room temperature around $20^{\circ} \mathrm{C}$. The crude products were dissolved in water, treated with $11 \mathrm{~mol} \%$ of $\mathrm{NaOH}$, and dialyzed extensively against water. Pure product alkyl-PEI25k was obtained as gummy solids on lyophilization and confirmed by ${ }^{1} \mathrm{H}$ NMR $\left(\mathrm{CDCl}_{3}\right)$.

Detailed synthetic method for attachment of DL-glycidol (GLY) to alkyl -PEI25k was described in a previous publication [25]. DL-Glycidol was purchased from Aladdin Reagent and used as received. A solution of DL-glycidol $(0.086 \mathrm{~g}, 1.16 \mathrm{mmol}$ for $10 \%$ functionalization) in methanol $(5 \mathrm{~mL})$ was added dropwise to a solution of alkyl-PEI $25 \mathrm{k}$ $(0.5 \mathrm{~g})$ in methanol $(5 \mathrm{~mL})$ at room temperature. The reaction mixture was stirred for one day. Subsequent removal of the solvent yielded a pale yellow viscous oily alkyl-PEI25kGLY. The degree of GLY grafting was calculated by ${ }^{1} \mathrm{H}$ $\mathrm{NMR}$ in $\mathrm{CDCl}_{3}$.

Conjugation of Cy5.5-NHS (Fanbo Biochemical, Beijing) on the surface of the amphiphilic PEI followed a recent publication [26]. Alkyl-PEI25k-GLY (20 mg, $0.8 \mu \mathrm{mol}$ ) dissolved in chloroform and added slowly into sodium phosphate buffer $\left(\mathrm{Na}_{2} \mathrm{HPO}_{4}\right.$ at $\left.\mathrm{pH} 8.4,0.1 \mathrm{~mol} / \mathrm{L}, 4 \mathrm{~mL}\right)$ with sonication. The mixture was under shaking for more than $24 \mathrm{~h}$ and remaining chloroform was removed through rotary evaporation. Then Cy5.5-NHS $(0.45 \mathrm{mg}, 0.4 \mu \mathrm{mol})$ dissolved in $100 \mu \mathrm{L}$ of buffer was added. After overnight incubation at $4{ }^{\circ} \mathrm{C}$ in the dark, the reaction mixture was dialyzed to remove the salt and unreacted Cy5.5. At last, the resultant was lyophilized to gummy solids. The fluorescence emission spectra of alkyl-PEI25k-GLY/Cy5.5 was measured in $\mathrm{H}_{2} \mathrm{O}$ by Fluorescence spectrophotometer (F-7000, Hitachi, Japan). The excitation wavelength was $620 \mathrm{~nm}$.

\subsection{Self-Assembly and characterization of amphiphilic alkyl-PEI25k-GLY/Cy5.5 /SPIO nanocomposites}

Amphiphilic alkyl-PEI25k-GLY/Cy5.5 was used to transfer SPIO nanocrystals from hexane into water. Briefly, SPIO nanocrystals in hexane were dried under argon and redispersed in chloroform together with varying amount of alkylated PEI. Then, mixed solution was slowly added into water with sonication. The mixture was under shaking for more than $24 \mathrm{~h}$ and remaining chloroform was removed through rotary evaporation. Water-soluble SPIO nanocomposites were characterized through DLS and atomic force microscopy (AFM).

\subsection{Cell uptake studies of imaging probes}

Multi-drug-resistant MCF-7 human breast cancer cells (MCF-7/Adr) were cultured in DMEM medium with $10 \%$ 
FBS, and maintained in a humidified atmosphere of 5\% $\mathrm{CO}_{2}$ at $37^{\circ} \mathrm{C}$, with the medium changed every other day. Confocal laser scanning microscopy (CLSM; TCS SP4, Leica Microsystems, Germany) was used to evaluate the cell labeling efficiency and intracellular distribution of alkyl-PEI25k-GLY/Cy5.5/SPIO micelles. MCF-7/Adr cells $\left(1 \times 10^{5}\right)$ were cultured on $35 \mathrm{~mm}$ glass-bottom culture dishes. After $24 \mathrm{~h}$, the cells were washed with PBS and then incubated at $37^{\circ} \mathrm{C}$ in the presence of multimodality probes at a Fe concentration of $7.5 \mu \mathrm{g} \mathrm{mL}^{-1}$ for different incubation periods $(3,6$, or $24 \mathrm{~h})$. Cells without imaging probe labeling were used as the control group. After the incubation period, cells were washed 3 times with PBS. Following fixation using a $4 \%$ paraformaldehyde solution, cellular nuclei were stained with 4',6-diamidino-2-phenyindole (DAPI, Sigma). The confocal microscope was equipped with DAPI and Cy5.5 filters, and cell images were captured with $\times 100 / 1.4$ PL APO oil-immersion objectives.

\subsection{MR and NIR fluorescence imaging studies of labeled cells}

To visualize MCF-7/Adr cells in a three-dimensional matrix by MRI, labeled and unlabeled cells were studied under clinical MRI scanners. In brief, cells were incubated with probes at a Fe concentration of $7.5 \mu \mathrm{g} \mathrm{mL}^{-1}$ for $24 \mathrm{~h}$, then fixed by paraformaldehyde and washed with PBS, at last, redispersed in a $5 \%$ gelatin phantom $(100 \mu \mathrm{L})$ crosslinked with glutaraldehyde inside microcentrifuge tubes. Serial dilutions of cells were prepared in gelatin phantom with a final number of $10^{6}, 5 \times 10^{5}, 2 \times 10^{5}, 10^{5}, 5 \times 10^{4}$ and $10^{4}$ MCF-7/Adr cells. MRI study of these cells was performed at 3 Tesla (Trio, Siemens) using a clinical head coil. $T_{2}$-weighted spin echo scans were used with the following parameters: $\mathrm{TR}=5000 \mathrm{~ms}$, TE from 10 to $500 \mathrm{~ms}$, number of averages $=1$, matrix $=384 \times 170, \mathrm{FOV}=250 \times$ $191 \mathrm{~mm}$, slice thickness $=2.0 \mathrm{~mm}$. Signal intensities of different TE time were used to calculate the $T_{2}$ value of each cell sample.

NIR fluorescence imaging can be used to visualize a group of cells labeled with multimodality probes. In vitro fluorescence imaging was performed with a Xenogen IVIS Spectrum imaging system (Xenogen, Alameda, CA, USA). Similar to the MR imaging study, MCF-7/Adr cells labeled with the nanoparticles with the cell number of $10^{6}, 5 \times 10^{5}$, $2 \times 10^{5}, 10^{5}, 5 \times 10^{4}$ and $10^{4}$ were separately dispersed in 100 $\mu \mathrm{L}$ PBS and pipetted into 96 well culture plate in black, while the unlabeled cells were used as control. The entire plate was imaged for $30 \mathrm{~s}$ using IVIS Spectrum in vivo imaging system. The fluorescence intensity for the cells was recorded as photons per second per centimeter squared per steradian divide per microwatt per centimeter squared $\left(\frac{\mathrm{p} \mathrm{s}^{-1} \mathrm{~cm}^{-2} \mathrm{sr}^{-1}}{\mu \mathrm{W} \mathrm{cm}}\right)$.

\section{Results and discussion}

\subsection{Synthesis and characterization of alkyl-PEI25k- GLY/Cy5.5}

The functional copolymers were synthesized by a three-step procedure (Scheme 1). The first step consists of the synthesis of amphiphilic graft copolymers through the alkylation of primary amine groups, followed by a typical nucleophilic reaction of DL-glycidol with some remaining primary amine groups to reduce the strong positive charge of PEI25k. Nanoparticles with positive charges have higher tendency to interact with cell membranes and uptake by cells, but strong charges may result in major particle attachment to the cell membrane instead of cell internalization. It has been shown that the attached particles can fall of from the cell membrane and resulted in false positive signaling in vivo [7]. The final step involves the conjugation of Cy5.5NHS on the surface of the amphiphilic PEI25k. In order to ensure the reaction yield of the final step and the solubility of functional PEI25k in organic solvents, we optimized the amount of alkylation grafts and DL-glycidol conjugation.

The partial alkylation was confirmed by ${ }^{1} \mathrm{H}$ NMR (400 $\mathrm{MHz}, \mathrm{CDCl}_{3}$, Figure 1(1)): $\delta(\mathrm{ppm}) 0.86-0.88\left(\mathrm{t},-\mathrm{CH}_{2}\right.$ $\left.\left(\mathrm{CH}_{2}\right)_{10} \mathrm{CH}_{3}\right), 1.25$ (br, $\left.-\mathrm{CH}_{2} \mathrm{CH}_{2}\left(\mathrm{CH}_{2}\right)_{9} \mathrm{CH}_{3}\right), 1.47$ (br, $\left.-\mathrm{CH}_{2} \mathrm{CH}_{2}\left(\mathrm{CH}_{2}\right)_{9} \mathrm{CH}_{3}\right), 2.5-2.8\left(\mathrm{~m},-\mathrm{CH}_{2} \mathrm{CH}_{2} \mathrm{NH}-,-\mathrm{CH}_{2}\right.$ $\mathrm{CH}_{2} \mathrm{~N}$-). It yielded a sample of N-dodecyl-PEI25k with about 10\% degree of substitution. Compared with alkylPEI25k, peaks corresponding to methylene protons next to hydroxyl group can be observed in the spectrum of alkylPEI25k-GLY (Figure 1(2)): ${ }^{1} \mathrm{H}$ NMR $\left(400 \mathrm{MHz}, \mathrm{CDCl}_{3}\right)$ : $\delta$ (ppm) $3.55\left(-\mathrm{CH}_{2} \mathrm{CHOHCH}_{2} \mathrm{OH}\right), 3.82\left(-\mathrm{CH}_{2} \mathrm{CHOHCH}_{2}\right.$ $\mathrm{OH})$. The integrals of the peaks corresponding to the methylene protons $\left(-\mathrm{CHCHOHCH}_{2} \mathrm{OH}, \delta 3.55\right)$ next to hydroxyl group and the PEI methylene protons $\left(-\mathrm{CH}_{2} \mathrm{CH}_{2} \mathrm{NH}-\right.$, $\delta$ 2.5-2.8 ppm) were used to determine the degree of GLY grafting, which is about $10 \%$.

The maximum excitation/emission wavelength of Cy5.5 is $674 / 697 \mathrm{~nm}$, and we chose the excitation wavelength of $620 \mathrm{~nm}$ to plot the fluorescence emission spectra to avoid unnecessary spectrum overlap caused by excitation at 674 $\mathrm{nm}$. Figure 2 shows the fluorescence emission spectrum of free Cy5.5 and alkyl-PEI25k-GLY/Cy5.5 micelle measured in $\mathrm{H}_{2} \mathrm{O}$. We found that the emission spectrum of alkylPEI25k-GLY/Cy5.5 micelle did not have obvious shift comparing to the free Cy5.5, suggesting that the hyperbranched PEI and conjugation process had little impact on the optical property of Cy5.5.

\subsection{Preparation and characterization of amphiphilic alkyl-PEI25k-GLY/Cy5.5/SPIO nanocomposites}

Lower alkyl-PEI25k/SPIO mass ratio $(<2.5)$ is able to form multiple SPIO nanocrystal containing micelles that have high $T_{2}$ relaxivities due to the clustering structures of SPIO 


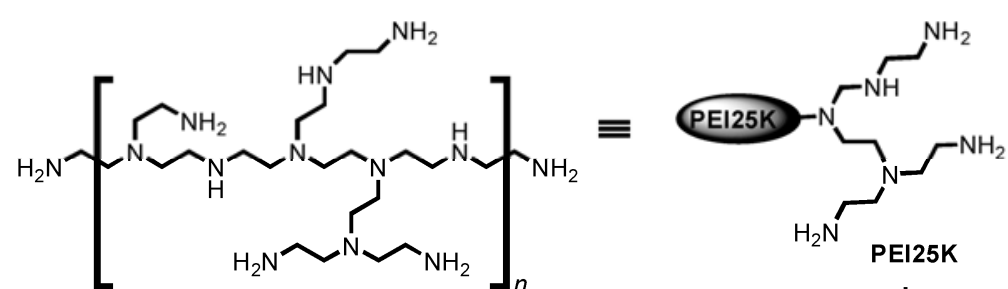

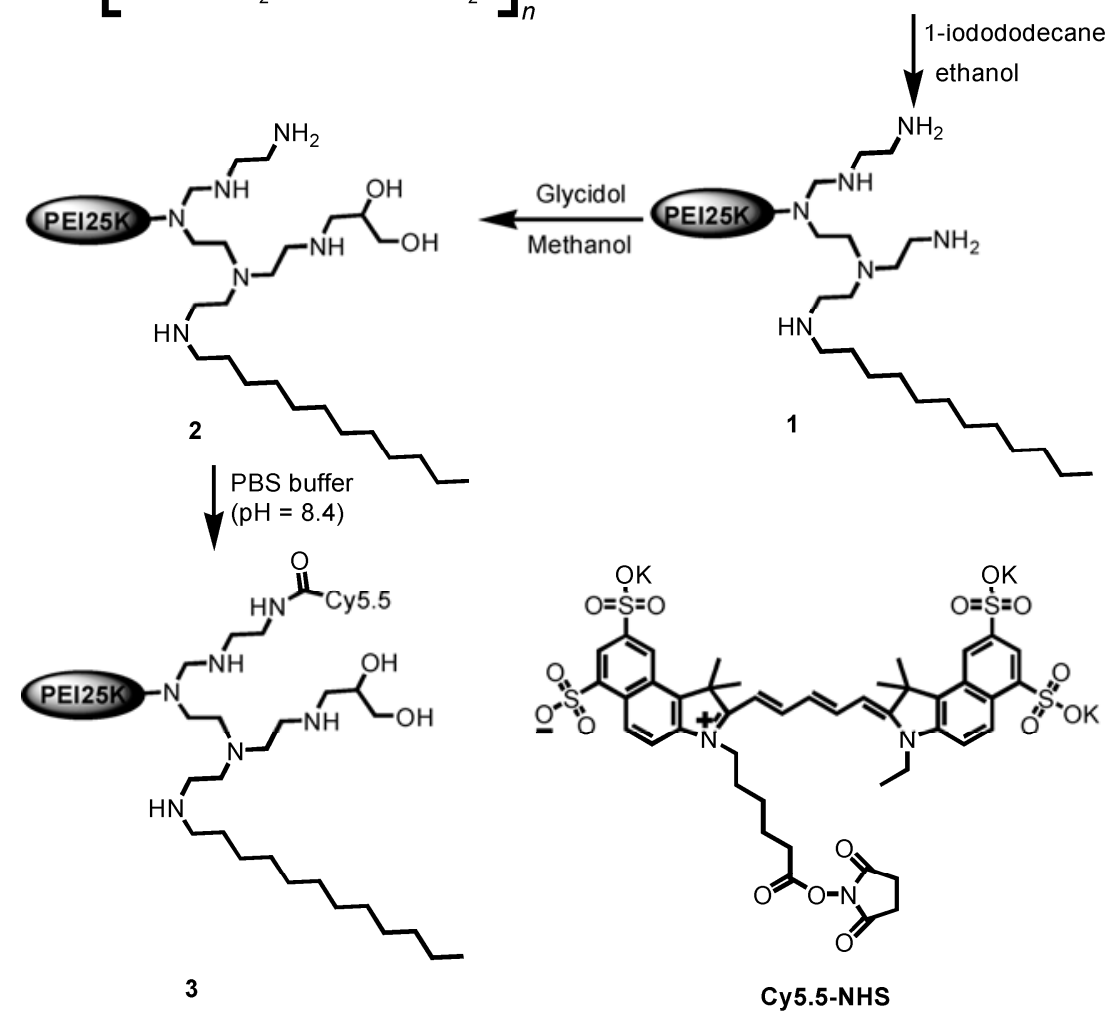

Scheme 1 The synthetic process of functional alkyl-PEI25k-GLY/Cy5.5

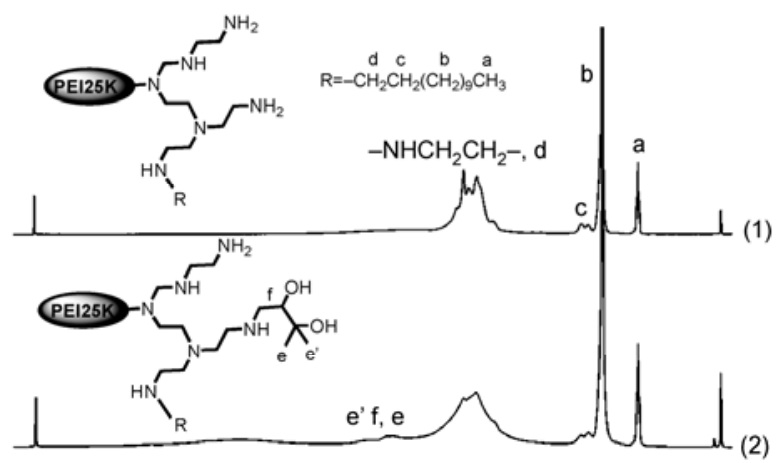

$\mathrm{ppm}_{7.0} \begin{array}{llllllllllllllllllll}1 & 6.0 & 5.5 & 5.0 & 4.5 & 4.0 & 3.5 & 3.0 & 2.5 & 2.0 & 1.5 & 1.0 & 0.5 & 0.0\end{array}$

Figure $1{ }^{1} \mathrm{H}$ NMR spectra of functional PEI25K $\left(\mathrm{CDCl}_{3}\right)$ (1) alkylPEI25k; (2) alkyl-PEI25k-GLY.

nanoparticles [27]. In addition, less amount of PEI will be used for cell labeling, as excess amount of PEI could lead to cell growth inhibition or even cell death. Based on the advantages of multiple SPIO nanocrystal containing nanocomposites, we chose the nanocomposites with alkylPEI25k-GLY/Cy5.5/SPIO mass ratio of 0.5 for our study.

The one-pot reaction led to the monodisperse SPIO

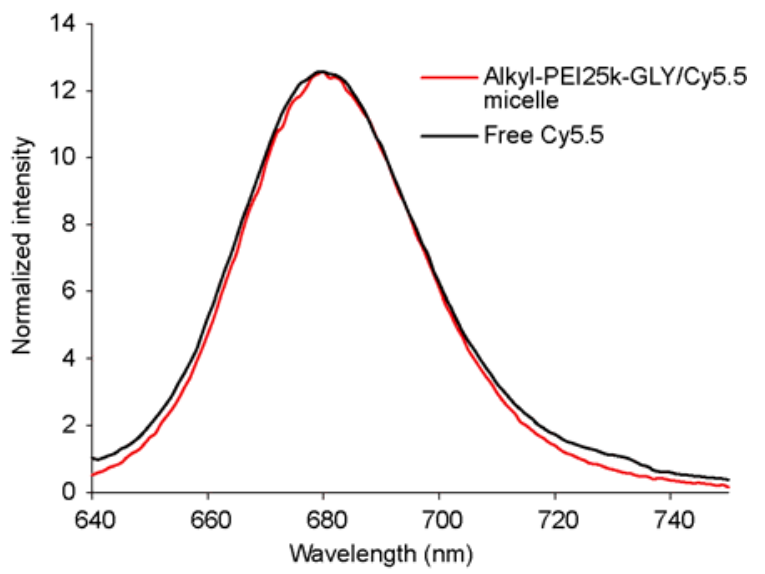

Figure 2 Emission spectra of free Cy5.5 and alkyl-PEI25k-GLY/Cy5.5 in water (Excitation wavelength: $620 \mathrm{~nm}$ ).

nanocrystals that can be easily isolated from the reaction byproducts and the ether solvent. Figure 3(a) displays the DLS data of SPIO nanocrystals in hexane with a diameter of $8.7 \pm$ $0.9 \mathrm{~nm}$. In comparison, the multifunctional nanocomposites in water have a diameter of $58.7 \pm 9.5 \mathrm{~nm}$ (Figure 3(b)). DLS 

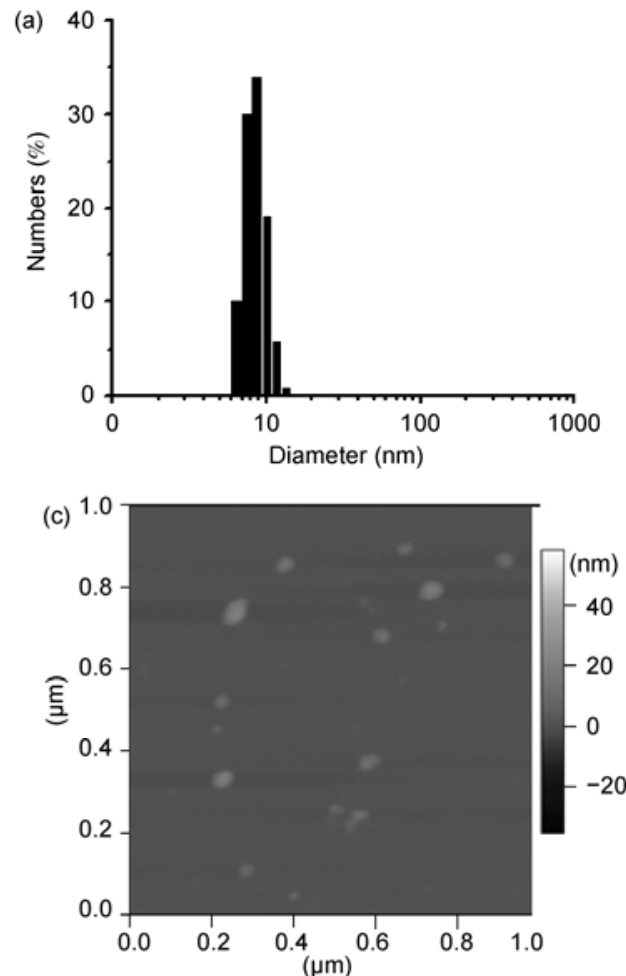
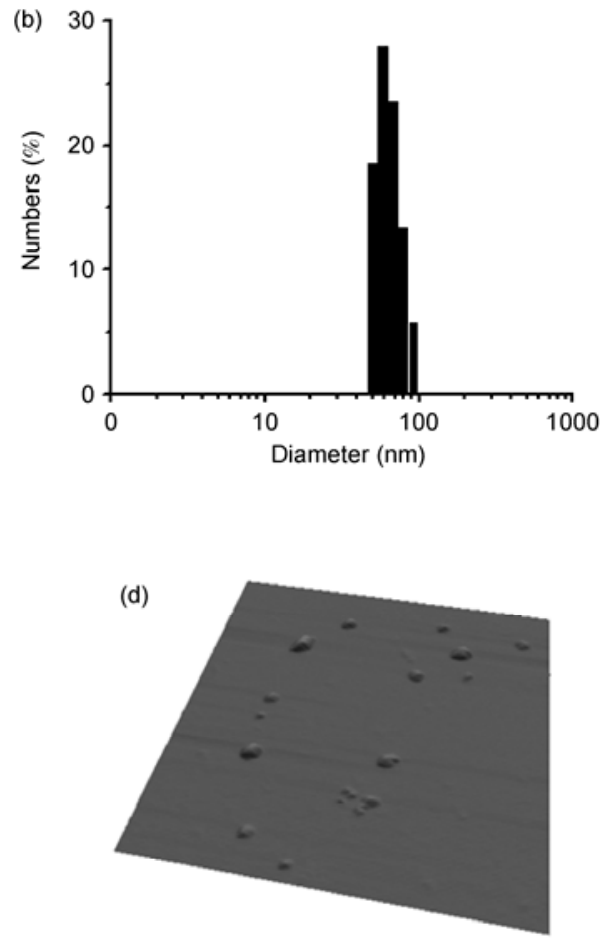

Figure 3 Characterization of the SPIO nanocomposites. (a) DLS of SPIO nanocrystals in hexane; (b) DLS of a alkyl-PEI25k-GLY/Cy5.5/SPIO nanocomposites with polymer/SPIO mass ratio of 0.5; (c) AFM height image of (b); (d) 3D AFM image of (b).

and AFM analysis demonstrated that the multifunctional nanocomposites were well dispersed without obvious aggregation and the size determined by AFM measurements was $64.2 \pm 12.2 \mathrm{~nm}$ (Figure 3(c),(d)). The increased diameter of the nanoparticles determined by AFM may be due to the particle-flattening on the mica surface during the drying process and the AFM tip broadening effect [28].

\subsection{Cell uptake studies of imaging probes}

Cell labeling efficiency and intracellular distribution of the nanocomposites was analyzed through CLSM (Figure 4). The confocal images for cell incubation either after 3 or $6 \mathrm{~h}$ confirmed that only a small amount of the nanoparticles were internalized by cells, but most particles were bound to cellular membranes due to the positive charge of particle surface. After $24 \mathrm{~h}$ incubation, cells have uptake more particles and appeared to be in the cytoplasm of cells, surrounding the nuclei. There was no obvious morphological change of the labeled cells comparing to the unlabeled ones. MRI probes internalized by tumor cells could allow prolonged imaging during tumor resection and serve as therapeutic drug carries for cancer therapy [21].

\subsection{MR and NIRF imaging studies of labeled cells}

The alkyl-PEI25k-GLY/Cy5.5/SPIO nanocomposites labeled

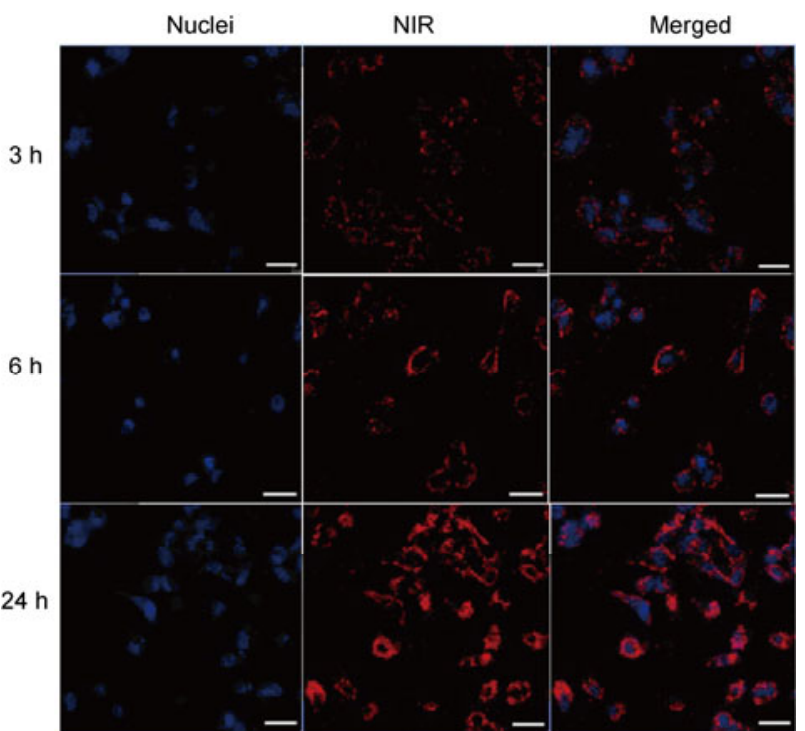

Figure 4 (Color online) CLSM images of MCF-7/Adr cells labeled with alkyl-PEI25k-GLY/Cy5.5/SPIO nanocomposites for 3, 6, $24 \mathrm{~h}$ at a Fe concentration of $7.5 \mu \mathrm{g} \mathrm{mL}^{-1}$. All the scale bars are 50 microns.

MCF-7/Adr cells were analyzed by relaxometry. After labeling at the iron concentration of $7.5 \mu \mathrm{g} \mathrm{mL}{ }^{-1}$ for $24 \mathrm{~h}$, cells were washed, collected and embedded into gelatin phantom for MRI study. Under $T_{2}$ scan (3T magnetic field), $10^{6}$ labeled cells displayed much darker MR images than cells without labeling (Figure 5). Long echo time (TE) led 


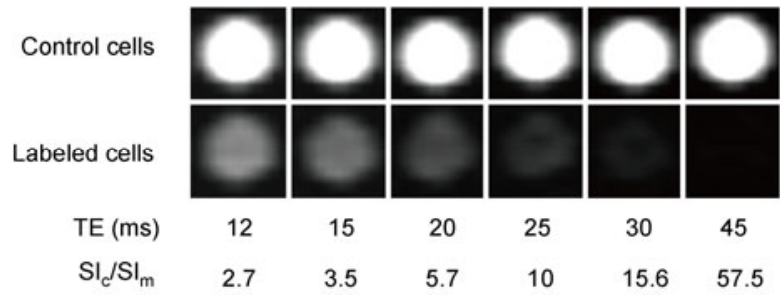

Figure $5 T_{2}$-weighted images ( $3 \mathrm{~T}$, spin-echo sequence: $\mathrm{TR}=5000 \mathrm{~ms}$, $\mathrm{TE}=12,15,20,25,30$, and $45 \mathrm{~ms}$ ) of control and imaging probe labeled cells $\left(1 \times 10^{6}\right)$ uniformly dispersed in gelatin phantom $(100 \mu \mathrm{L})$ in microcentrifuge tubes. The ratios of signal intensities of the control sample $\left(\mathrm{SI}_{\mathrm{c}}\right)$ and the labeled one $\left(\mathrm{SI}_{\mathrm{m}}\right)$ are listed below the TE times.

to an increased signal contrast between labeled and control cells. At a TE of $45 \mathrm{~ms}$, the signal intensity of controlled cells $\left(\mathrm{SI}_{\mathrm{c}}\right)$ is 57.5 times of the labeled cells $\left(\mathrm{SI}_{\mathrm{m}}\right)$, comparing to the 2.7 times difference at a short TE of $12 \mathrm{~ms}$. It is likely that cells labeled with alkyl-PEI25k-GLY/Cy5.5/SPIO agents can shorten the spin-spin relaxation time $\left(T_{2}\right)$ by dephasing the spins of neighboring water protons and result in darkening of $T_{2}$-weighted images comparing to controlled ones. The relaxation rate $\left(1 / T_{2}\right)$ of labeled cells is $98.2 \mathrm{~s}^{-1}$, significantly higher than the controlled cells of $2.3 \mathrm{~s}^{-1}$. The $T_{2}$ relaxation enhancement is appreciable as comparing to a similar probe based on N-dodecyl-PEI25k/SPIO composites used for stem cell labeling, resulting a $1 / T_{2}$ value of $74.2 \mathrm{~s}^{-1}$ at the magnetic field of $3 \mathrm{~T}$ [27].

To investigate the MRI sensitivity of the SPIO probe labeling, we tested imaging of labeled cells in vitro. $T_{2}$ values decreased from 160.2 to $10.2 \mathrm{~ms}$ with the increase of cell number (from $5 \times 10^{4}$ to $10^{6}$ ), which could provide noticeable signal contrast to cells during tracking procedure (Figure 6).

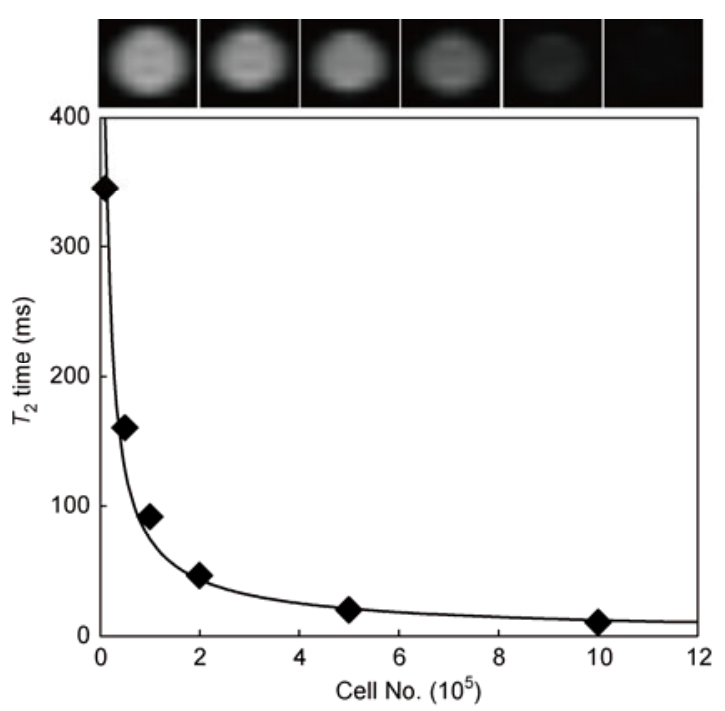

Figure $6 T_{2}$ values (3T, spin echo acquisition) of alkyl-PEI25k-GLY/ Cy5.5/SPIO nanocomposites labeled cells in gelatin phantom in microcentrifuge tubes as a function of cell number. Upper panel MR images are cross sections of corresponding tubes under SE acquisition (TR $=5000 \mathrm{~ms}$, $\mathrm{TE}=35 \mathrm{~ms}$ )
The result is consistent with our previous study that $T_{2}$ values decreased from $115 \mathrm{~ms}$ to $12.2 \mathrm{~ms}$ with an increase of cell number (from $5 \times 10^{4}$ to $10^{6}$ ) for stem cells labeled with N-dodecyl-PEI25k/SPIO composites [27]. Moreover, the $T_{2}$ relaxation rate of $5 \times 10^{4}$ cells is $6.2 \mathrm{~s}^{-1}$, and still more than twice of the controlled cells $\left(2.3 \mathrm{~s}^{-1}\right)$. When used for in vivo monitoring purpose, usually $5 \times 10^{5}$ to $3 \times 10^{7}$ cells were transplanted or injected into small animal models [29,30]. It is possible that SPIO micelle labeled cells would provide noticeable signal contrast to other cells during tracking procedure. The tracking ability may be useful to understand certain disease development pathways or monitor cell therapy efficacy.

The development of NIR fluorescence imaging system has been proven to be a very powerful tool for noninvasive imaging of diseases in preclinical models [31] with high sensitivity. We monitored the fluorescence intensity of the cells labeled with dual modality nanocomposites using the IVIS Spectrum imaging system. Figure 7 shows typical NIR fluorescence images of MCF-7/Adr cells. We found that the fluorescence intensity was enhanced with the increase of cell numbers. The signal intensity was quantified by ROI analysis of images, indicating the intensity of $10^{6}$ cells is more than twice of that of the $2 \times 10^{5}$ cells. Cells $\left(10^{6}\right)$ without probing labeling did not display any obvious fluorescence.

\section{Conclusion}

In conclusion, iron oxide nanoparticles can be self-assembled into nanocomposites in water with the help of alkyl-PEI25-GLY conjugated with Cy5.5, creating a multifunctional nanoprobe that detectable both magnetically and optically. Confocal laser scanning microscopy reveals that the nanoprobes are internalized into the cytoplasm of MCF-7/Adr after labeling $24 \mathrm{~h}$. Labeled cells present obvious MR signal darkening comparing to the untreated ones when observed under a clinical 3T MRI scanner. Labeled cells present strong NIR fluorescence comparing to unlabeled ones in vitro. The in vivo application of such dual modality probe is under investigation.

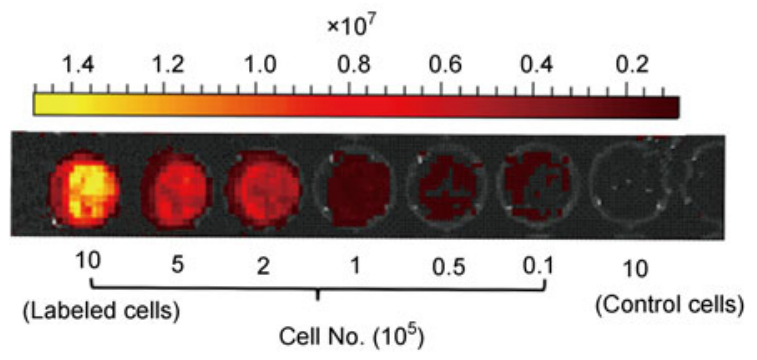

Figure 7 (Color online) In vitro optical images of alkyl-PEI25k-GLY/ Cy5.5/SPIO nanocomposites labeled cells in PBS as a function of cell number. Excitation wavelength: $640 \mathrm{~nm}$; emission wavelength: $700 \mathrm{~nm}$. 
This work was supported by the Program for New Century Excellent Talents in University (NCET-06-0781), the Distinguished Young Scholars Project of Sichuan Province (06ZQ026-007), the Doctoral Fund of Ministry of Education of China (20090181110068), and the National Natural Science Foundation of China (20974065, 51173117 and 50830107).

1 Brigger I, Dubernet C, Couvreur P. Nanoparticles in cancer therapy and diagnosis. Adv Drug Deliv Rev, 2002, 54: 631-651

2 Ferrari M. Cancer nanotechnology: Opportunities and challenges. Nat Rev Cancer, 2005, 5: 161-171

3 Peer D, Karp J M, Hong S, et al. Nanocarriers as an emerging platform for cancer therapy. Nat Nanotechnol, 2007, 2: 751-760

4 Shuai X T, Ai H, Nasongkla N, et al. Micellar carriers based on block copolymers of poly(e-caprolactone) and poly(ethylene glycol) for doxorubicin delivery. J Control Release, 2004, 98: 415-426

5 Wood K C, Azarin S M, Arap W, et al. Tumor-targeted gene delivery using molecularly engineered hybrid polymers functionalized with a tumor-homing peptide. Bio Chem, 2008, 19: 403-405

6 Kozlowska D, Foran P, MacMahon P, et al. Molecular and magnetic resonance imaging: The value of immunoliposomes. Adv Drug Delivery Rev, 2009, 61: 1402-1411

7 Bulte J W M, Kraitchman D L. Iron oxide MR contrast agents for molecular and cellular imaging. NMR Biomed, 2004, 17: 484-499

8 Janib S M, Moses A S, MacKay J A. Imaging and drug delivery using theranostic nanoparticles. Adv Drug Delivery Rev, 2010, 62: 1052-1063

9 Rudin M, Weissleder R. Molecular imaging in drug discovery and development. Nat Rev Drug Discov, 2003, 2: 123-131

10 Willmann J K, van Bruggen N, Dinkelborg L M, et al. Molecular imaging in drug development. Nat Rev Drug Discovery, 2008, 7: 591-607

11 Ai H. Layer-by-layer capsules for magnetic resonance imaging and drug delivery. Adv Drug Delivery Rev, 2011, 63: 772-788

12 Ai H, Flask C, Weinberg B, et al. Magnetite-loaded polymeric micelles as ultrasensitive magnetic-resonance probes. Adv Mater, 2005, 17: 1949-1956

13 Wang Y X, Hussain S M, Krestin G P. Superparamagnetic iron oxide contrast agents: Physicochemical characteristics and applications in MR imaging. Eur Radiol, 2001, 11: 2319-2331

14 Thorek D L J, Chen A, Czupryna J, et al. Superparamagnetic iron oxide nanoparticle probes for molecular imaging. Ann Biomed Eng, 2006, 34: 23-38

15 Taktak S, Sosnovik D, Cima M J, et al. Multiparameter magnetic relaxation switch assays. Anal Chem, 2007, 79: 8863-8869

16 Liu G, Wang Z, Lu J, et al. Low molecular weight alkyl-polycation wrapped magnetite nanoparticle clusters as MRI probes for stem cell labeling and in vivo imaging. Biomaterials, 2011, 32: 528-537

17 Liu G, Xia C, Wang Z, et al. Magnetic resonance imaging probes for labeling of chondrocyte cells. J Mater Sci-Mater Med, 22: 601606

18 Chen X Y, Conti P S, Moats R A. In vivo near-infrared fluorescence imaging of integrin $\alpha_{v} \beta_{3}$ in brain tumor xenografts. Cancer Res, 2004, 64: 8009-8014

19 Becker A, Hessenius C, Licha K, et al. Receptor-targeted optical imaging of tumors with near-infrared fluorescent ligands. Nat Biotechnol, 2001, 19: 327-331

20 Weissleder R, Tung $\mathrm{C} \mathrm{H}$, Mahmood $\mathrm{U}$, et al. In vivo imaging of tumors with protease-activated near-infrared fluorescent probes. Nat Biotechnol, 1999, 17: 375-378

21 Veiseh O, Sun C, Gunn J, et al. Optical and MRI multifunctional nanoprobe for targeting gliomas. Nano Lett, 2005, 5: 1003-1008

22 Talanov V S, Regino C A S, Kobayashi H, et al. Dendrimer-based nanoprobe for dual modality magnetic resonance and fluorescence imaging. Nano Lett, 2006, 6: 1459-1463

23 Sun S H, Zeng H, Robinson D B, et al. Monodisperse $\mathrm{MFe}_{2} \mathrm{O}_{4}(\mathrm{M}=$ $\mathrm{Fe}, \mathrm{Co}, \mathrm{Mn}$ ) nanoparticles. J Am Chem Soc, 2004, 126: 273-279

24 Wang Q, Su H, Xia C, et al. Amphiphilic dextran/magnetite nanocomposites as magnetic resonance imaging probes. Chin Sci Bull, 2009, 54: 2925-2933

25 Kramer M, Perignon N, Haag R, et al. Water-soluble dendritic architectures with carbohydrate shells for the templation and stabilization of catalytically active metal nanoparticles. Macromolecules, 2005, 38: 8308-8315

26 Cheng Z, Levi J, Xiong Z M, et al. Near-infrared fluorescent deoxyglucose analogue for tumor optical imaging in cell culture and living mice. Bioconj Chem, 2006, 17: 662-669

27 Zhiyong W, Gang L, Jiayu S, et al. Self-assembly of magnetite nanocrystals with amphiphilic polyethylenimine: Structures and applications in magnetic resonance imaging. J Nanosci Nanotechnol, 2009, 9: $378-385$

28 Wilson D L, Kump K S, Eppell S J, et al. Morphological restoration of atomic-force microscopy imaging. Langmuir, 1995, 11: 265-272

29 Kircher M F, Allport J R, Graves E E, et al. In vivo high resolution three-dimensional imaging of antigen-specific cytotoxic T-lymphocyte trafficking to tumors. Cancer Res, 2003, 63: 6838- 6846

30 Song H T, Choi J S, Huh Y M, et al. Surface modulation of magnetic nanocrystals in the development of highly efficient magnetic resonance probes for intracellular labeling. J Am Chem Soc, 2005, 127: 9992-9993

31 Ntziachristos V, Bremer C, Weissleder R. Fluorescence imaging with near-infrared light: New technological advances that enable in vivo molecular imaging. Eur Radio, 2003, 13: 195-208

Open Access This article is distributed under the terms of the Creative Commons Attribution License which permits any use, distribution, and reproduction in any medium, provided the original author(s) and source are credited. 